\title{
Higher percentage of horse serum in culture media blocks attachment of $\mathrm{PC} 12$ cells
}

\author{
Jennifer L Meth' \& Alan R Schoenfeld*,1
}

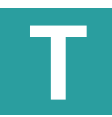

he rat pheochromocytoma cell line, PC12, has become a major model system to study many aspects of neuronal activity since its development and characterization in the 1970s [1]. One of its most useful properties is that, following stimulation by nerve growth factor (NGF), these cells extend processes or neurites in a differentiation program that is reversible upon NGF removal. The NGF-mediated differentiation includes the formation of functional synapses as well as electrical excitability $[2,3]$. Because of these remarkable properties, PC12 cells have been an important tool to uncover the mechanisms of neuronal differentiation as well as the NGF signaling pathway. PC12 cells have also been used extensively to study exocytosis, especially of catecholamines (reviewed in [4]).

According to their initial characterization [1], PC12 cells are round or polygonal, loosely adherent, and tend to grow in clumps. We report here that their cellular morphology and adherence is affected greatly by the percentage of horse serum contained in their culture medium. While the original growth conditions in Greene and Tischler specify the addition of $10 \%$ horse serum and $5 \%$ fetal calf serum (FCS) in the growth medium, which is reinforced by recommendations of the culture repository, ATCC, not all researchers use the same amount of horse serum in their $\mathrm{PC} 12$ cultures. Although 10\% horse serum is most common, amounts ranging between

\section{KEYWORDS}

cell attachment $\cdot$ differentiation $\cdot$ horse serum - neurite outgrowth $\cdot \mathrm{PC} 12$

'Department of Biology, Adelphi University, Garden City, NY 11530-0701, USA; *Author for correspondence: schoenfeld@adelphi.edu

BioTechniques 67: 256-258 (December 2019) 10.2144/ btn-2019-0073 as low as 5\% [5] and as high as 15\% [6] have been used. Moreover, reasons for utilizing a specific concentration of horse serum are routinely not provided and the literature also lacks sufficient explanation as to its effects. We initially observed, after changing our source of horse serum, that a larger percentage of cells were more rounded and seemingly loosely attached several days after plating, which led us to further analyze the effects of horse serum on the growth of $\mathrm{PC} 12$ in culture.

$\mathrm{PC} 12$ cells were grown in DMEM media supplemented with increasing percentages of horse serum $(0,2.5,5,10$ and $15 \%)$. Two different sources of horse serum were used: Donor Equine Serum from either Corning or HyClone (GE Healthcare Life Sciences). However, because the focus here is the percentage of horse serum and not variations between manufacturers (or lots), these two sources are referred to herein simply as horse serum 1 and 2 , in no particular order with respect to the manufacturers named above. The percentage of cells that were loosely attached (rounded) was determined for each culture condition, as described in Figure 1. At $24 \mathrm{~h}$ post-plating (Figure 1A), as horse serum percent increased, there was a statistically significant, dose-dependent increase in the percentage of cells that were loosely attached ( $p<0.001$ for all comparisons, except 0 vs $2.5 \%$ horse serum, for which $p=0.103$ ). With 10 and $15 \%$ horse serum, the majority of cells were loosely attached at the 24-h time point. At $48 \mathrm{~h}$ post-plating (Figure 1B), with horse serum between $0 \%$ and $10 \%$, the majority of cells were polygonal and attached, with 10\% horse serum showing considerably more cells that were loosely attached than the lower percentages $(\mathrm{p}<0.001$ in comparison with $0,2.5$ and $5 \%$ horse serum). At $15 \%$ horse serum, the majority of the cells were loosely attached at $48 \mathrm{~h}$ post-plating ( $p<0.001$ for all comparisons). These results indicate that higher percentages of horse serum in the culture media prevent attachment and spreading of PC12 cells toward a polygonal morphology and lead to more loosely attached (rounded) cells.

To determine whether the horse serummediated differences in cell morphology had a functional effect on the PC12 cells, neurite outgrowth assays were performed, as described in Figure 2. Preincubation with the range of horse serum percentages did not show a statistically

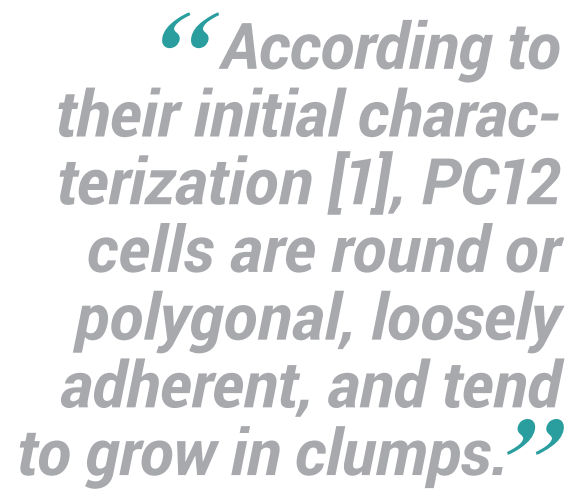

significant difference in neurite outgrowth. Although there was substantial neurite outgrowth following preincubation with all percentages of horse serum (including $0 \%$ ), there was more variability when using lower percentages (i.e., 0, 2.5 and 5\%), and while the higher percentages (i.e., 10 and $15 \%$ ) did seem to foster slightly more neurite outgrowth, there was at best marginal significance, with the comparison of 5 versus $10 \%$ horse serum preincubation coming the closest to achieving statistical significance $(p=0.078)$. Thus, while variations in horse serum percentage led to differences in morphology of the PC12 cells prior to NGF-mediated differentiation, they do not seem to overtly change the ability of these cells to differentiate in response to NGF.

Overall, the results contained herein suggest that the choice of horse serum 


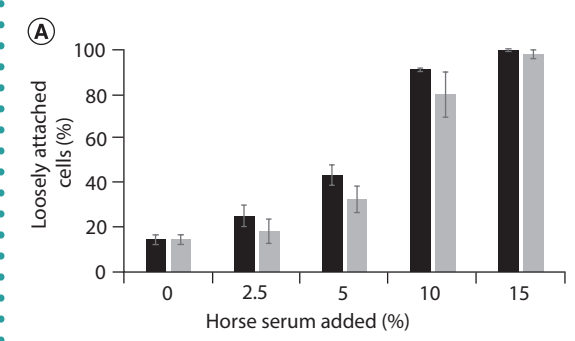

(B)

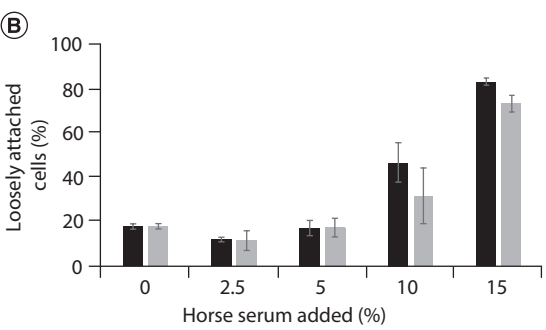

(c)

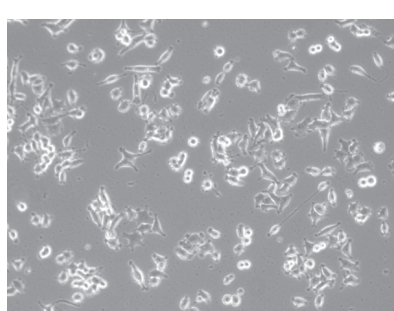

Figure 1. Percent of loosely attached (rounded) PC12 cells. PC12 cells were plated in standard culture dishes in media containing the indicated combination of horse serum and fetal calf serum. Images captured using a Zeiss Primovert inverted microscope (at $40 \times$ magnification) equipped with an Excelis high-definition digital camera after (A) $24 \mathrm{~h}$ and (B) $48 \mathrm{~h}$ were analyzed blindly, counting the percentage of cells loosely attached, as judged by a halo around the cells in the image and a lack of extensions from the cell body. Cell counts from three images for each combination were averaged. For statistical analyses, ANOVA with Tukey HSD post-hoc tests were performed. (Note: In both (A) and (B), there was no statistically significant difference between horse serums 1 and 2 at any of the horse serum percentages). (C) A representative image showing loosely attached cells with halos and attached (polygonal) cells.

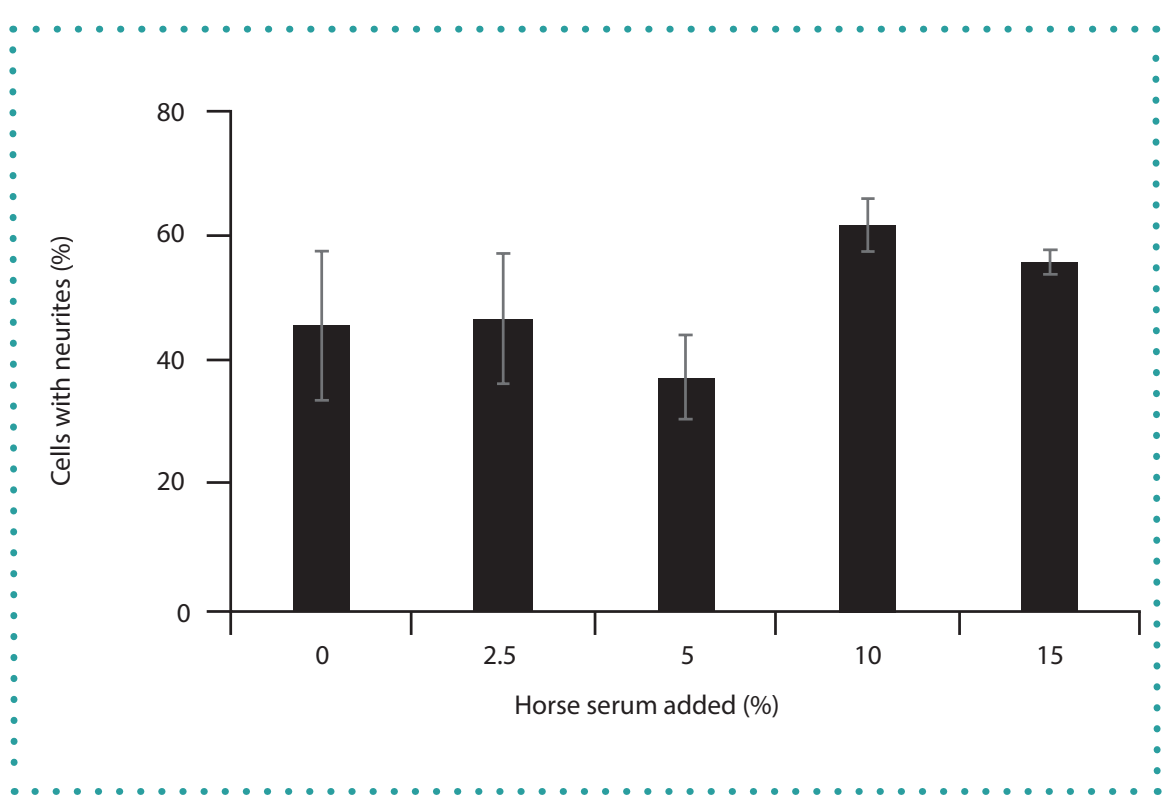

Figure 2. Neurite outgrowth assay. Wells in six-well plates were incubated with $0.5 \mathrm{ml}$ of a $20 \mu \mathrm{g} / \mathrm{ml}$ solution of laminin (Sigma) and allowed to dry. DMEM media containing the indicated percentages of horse serum along with $5 \%$ fetal calf serum were added to the wells ( 3 wells for each horse serum percentage). PC12 cells $\left(1 \times 10^{4}\right.$ cells) were added to each well and allowed to attach for $48 \mathrm{~h}$. Media was replaced with serum-free DMEM, supplemented with $100 \mathrm{ng} / \mathrm{ml}$ of NGF (Becton Dickenson), and the cells were allowed to incubate for another $48 \mathrm{~h}$. Five images from each well were captured using a Zeiss Primovert inverted microscope (at 100× magnification). Cells from each image were counted, both total cells and those with neurites, defined as neuronlike extensions of the cell membrane that were equal to or longer than one diameter of the cell. For statistical analyses, ANOVA with Tukey HSD post-hoc tests were performed.
- percentage used by researchers is mostly a matter of choice, reflecting their culture preferences. As the most common percentages of horse serum used seem to be 10 and 15\%, which led to fairly similar performance in neurite outgrowth, the more loosely attached (rounded) cells seen with $15 \%$ horse serum may be preferred by researchers that do not use trypsin to subculture PC12 cells, allowing them to grow more as a suspension culture. Of note, our initial observation of changed culture characteristics upon switching horse serum sources, which caused us to consider discarding the horse serum, can be simply remedied by altering horse serum concentration.

One question perhaps worthy of further investigation is the effect of long-term culturing of PC12 cells in medium either devoid of horse serum or containing lower percentages. The more attached polygonal cells observed with low horse serum percentages (short term) in this report may be associated with partial differentiation of these cells toward a non-neuronal cell type that can be reversed by removal of serum and addition of NGF. It is currently unclear what role the horse serum plays in $\mathrm{PC} 12$ cell culture, but given that $\mathrm{PC} 12 \mathrm{~s}$ are progenitor cells and can differentiate along both chromaffin and sympathetic neuronal lineages [1], horse serum may preserve the progenitor status of these cells. Along these lines, horse serum has also been used to maintain hematopoietic progenitor cells in culture, keeping them in a less differentiated state [7,8], and has been seen to block the differentiation of hepatic progenitor cells [9]. Thus, future studies could further clarify the effect of horse serum on the differentiation state of $\mathrm{PC} 12$ cells.

The discrepancies in PC12 cell attachment seen with different horse serum sources are likely due to differences in the levels of some factor(s) in these sera. Thus, another potential avenue of future studies is to determine which components in horse serum mediate the effect seen on PC12 attachment and are responsible for the variances observed. Unlike human serum, for which the composition has been characterized [10], sera used in tissue culture are usually minimally defined and the proteins, lipids, and/or growth factors and hormones contained in them may vary among sources 


\section{"One question perhaps worthy of further investigation is the effect of long-term culturing of PC12 cells in medium either devoid of horse serum or containing lower percentages."}

for many reasons [11,12]. Ditz et al. were able to determine that high levels of fatty acid products of phospholipase A2, notably eicosanoids, present in some lots of horse serum inhibited self-renewal of multipotent murine hematopoietic progenitor cells [8]. While it is possible that these compounds may similarly affect PC12 cells, identification of the actual components of horse serum that inhibit attachment (and preserve progenitor status) is needed, which would allow elucidation of the underlying cellular pathways and mechanisms as well.

\section{AUTHOR CONTRIBUTIONS}

JLM carried out all of the experiments and the majority of the data analysis. ARS completed the data analysis, performed statistical analysis, and wrote the manuscript.

\section{ACKNOWLEDGMENTS}

The authors thank Benjamin Weeks (Adelphi University) for generously supplying the PC12 cells, which were originally obtained from G Guroff (NIH).

\section{FINANCIAL \& COMPETING INTERESTS DISCLOSURE}

Research reported in this publication was supported by the National Cancer Institute of the National Institutes of Health (award number R15CA121992). The authors have no other relevant affiliations or financial involvement with any organization or entity with a financial interest in or financial conflict with the subject matter or materials discussed in the manuscript apart from those disclosed.

No writing assistance was utilized in the production of this manuscript.

\section{OPEN ACCESS}

This work is licensed under the AttributionNonCommercial-NoDerivatives 4.0 Unported License. To view a copy of this license, visit http://creativecommons.org/ licenses/by-nc-nd/4.0/

\section{REFERENCES}

1. Greene LA, Tischler AS. Establishment of a noradrenergic clonal line of rat adrenal pheochromocytoma cells gic clonal line of rat adrenal pheochromocytoma cells
which respond to nerve growth factor. Proc. Natl Acad. which respond to nerve growth factor.
Sci. USA 73), 2424-2428 (1976).

2. Dichter MA, Tischler AS, Greene LA. Nerve growth factor-induced increase in electrical excitability and
acetylcholine sensitivity of a rat pheochromocytoma cell line. Nature 268(5620), 501-504 (1977).

3. Schubert D, Heinemann S, Kidokoro Y. Cholinergic metabolism and synapse formation by a rat nerve cell line. Proc. Natl Acad. Sci. USA 74(6), 2579-2583 (1977).

4. Westerink RH, Ewing AG. The PC12 cell as model for neurosecretion. Acta Physiol. 192(2), 273-285 (2008).

5. Martin TF, Grishanin RN. PC12 cells as a model for studies of regulated secretion in neuronal and endocrine cells. Methods Cell Bio. 171, 267-286 (2003).

6. luvone T, Esposito G, Esposito R, Santamaria R, Di Rosa M, Izzo AA. Neuroprotective effect of cannabidiol, a non-psychoactive component from Cannabis sativa, on beta-amyloid-induced toxicity in PC12 cells. J. Neurochem. 89(1), 134-141 (2004).

7. Spooncer E, Heyworth CM, Dunn A, Dexter TM. Self-renewal and differentiation of interleukin-3-dependent newal and differentiation of interleukin-3-dependent
multipotent stem cells are modulated by stromal cells and serum factors. Differentiation 31(2), 111-118 (1986).

8. Ditz T, Schnapka-Hille L, Noack $\mathrm{N}$ et al. Phospholipase A2 products predict the hematopoietic support capacity of horse serum. Differentiation 105, 27-32 (2019).

9. Hui $\mathrm{H}, \mathrm{Ma} W$, Cui J et al. Periodic acid-Schiff staining method for function detection of liver cells is affected by $2 \%$ horse serum in induction medium. Mol. Med. Rep. 16(6), 8062-8068 (2017).

10. Psychogios N, Hau DD, Peng J et al. The human serum metabolome. PLoS One 6(2), e16957 (2011).

11. van der Valk J, Brunner D, De Smet K et al. Optimization of chemically defined cell culture media - replacing fetal bovine serum in mammalian in vitro methods. Toxicol. Vitr. 24(4), 1053-1063 (2010).

12. Baker M. Reproducibility. Respect your cells! Nature 537(7620), 433-435 (2016). 